\title{
Morfometria e estereologia testicular de ratos adultos tratados com ciclofosfamida incorporada ao lipossoma
}

\author{
Testicular morphometry and stereology of adult rats treated with \\ cyclophosphamide incorporated to the liposome
}

\author{
Isabel Cristina Cherici Camargo ${ }^{1}$; Lázaro Cícero Nogueira ${ }^{1}$; Davi Abeid Pontes ${ }^{2}$; \\ Ana Paula Alves Favareto ${ }^{2}$; Fernando Frei $^{3}$; Suzana de Fátima Paccola Mesquita ${ }^{4}$
}

\section{Resumo}

Lipossomas representam um benéfico sistema de transporte de fármacos que é utilizado em estudos clínicos para atuar como um veículo não tóxico, reduzindo os efeitos colaterais e aumentando a eficácia de agentes antitumorais. O objetivo deste estudo é investigar, por meio de parâmetros morfométricos e estereológicos, os efeitos da ciclofosfamida incorporada aos lipossomas, em testículos de ratos adultos. Como resultado, a incorporação do agente oncolítico aos lipossomas mostrou, em primeiro lugar, aumento no peso e volume testicular, assim como aumento no diâmetro e área dos túbulos seminíferos.Para o grupo tratado com ciclofosfamida incorporada aos lipossomas as diferenças nos volumes testicular e do parênquima mostraram-se não significativas em relação ao grupo controle.Os resultados indicam que a incorporação da droga ao lipossoma reduz os efeitos colaterais sobre a gônada masculina.

Palavras-chave: Lipossoma. Ciclofosfamida. Testículo. Morfometria. Estereologia.

\begin{abstract}
Liposomes represent a useful drug carrier system which is utilized in clinical studies to act as a non-toxic vehicle, reducing side effects and increasing the efficacy of antitumor agents. The aim of this study is to investigate, by means of morphometric and stereologic parameters, the effects of the cyclophosphamide, incorporated to liposomes, in testis of adult rats. As a result, the incorporation of the oncolytic agent to the liposomes showed, in the first place, increase of the testicular weight and volume, as well as an extension in diameter and area of the seminiferous tubules. For the group treated with cyclophosphamide incorporated to liposomes the differences in testicular and parechyma volumes showed non-significant with respect to the control group. Results indicate that the incorporation of the drug to the liposome reduces side effects on the male gonad.
\end{abstract}

Key words: Liposome. Cyclophosphamide. Testis. Morphometry. Stereology.

1 Docente do Departamento de Ciências Biológicas da Faculdade de Ciências e Letras - Universidade Estadual Paulista-UNESP, Assis (SP). E-mail: camargo@ assis.unesp.br.

2 Acadêmicos do Curso de Graduação em Ciências Biológicas da Faculdade de Ciências e Letras - Universidade Estadual Paulista - UNESP, Assis (SP).

3 Docente do Departamento de Psicologia Experimental e do Trabalho da Faculdade de Ciências e Letras - Universidade Estadual Paulista - UNESP, Assis (SP).

${ }_{4}$ Docente do Departamento de Biologia Geral, Universidade Estadual de Londrina - UEL, Londrina (PR). 


\section{Introdução}

Lipossomas são vesículas microscópicas estáveis, formadas por fosfolipídios e lipídios anfipáticos similares que, em meio aquoso, formam bicamadas lipídicas semelhantes estruturalmente às membranas biológicas celulares. Esta similaridade permite que os lipossomas possam ser administrados sem efeitos colaterais (SCULIER et al., 1989).

Desde que GREGORIADIS et al. (1971) descreveram a capacidade de os lipossomas transportarem e liberarem agentes terapêuticos, vários estudos clínicos têm demonstrado que a incorporação de fármacos ao lipossoma permite o aumento da eficácia e a redução dos efeitos colaterais. Várias drogas (imunomoduladores, agentes oncolíticos, antibióticos, produtos oftálmicos, antiasmáticos, antifúngicos, vacinas, promotores do crescimento capilar e protetores gástricos) estão sendo investigadas para futuras aplicações farmacêuticas.

A capacidade de o lipossoma não afetar a farmacocinética e a distribuição da droga (JULIANO, 1981; LEVY, 1987), e ser um veículo não-tóxico (LIDGATE et al., 1988), constituem as principais vantagens de seu uso no transporte de fármacos. Além disso, devido à sua biocompatibilidade, os lipossomas podem ser aplicados por qualquer via de administração (FIELDING, 1991). Quando injetados por via subcutânea ou intramuscular, fornecem um reservatório de liberação prolongada do fármaco para atuação local ou sistêmica (FIELDING, 1991). As vias intraperitoneal e intratecal também têm sido estudadas (KIM et al., 1987; DELGADO et al., 1989), mas os trabalhos científicos enfatizam extensivamente a administração intravenosa e a inalação.

Estudos em ratos e camundongos demonstraram que vários órgãos como fígado, rins, pulmões, músculo esquelético e cérebro, são capazes de absorver lipossomas injetados no organismo (GREGORIADIS, 1976).

Entre as drogas amplamente utilizadas na clínica médica para o tratamento de artrite reumática e neoplasias em geral, salienta-se a ciclofosfamida. Trata-se de um agente alquilante, efetivo contra tumores de crescimento lento, que danifica células em quaisquer fases de crescimento celular. Os agentes alquilantes têm a propriedade de se tornarem potentes eletrófilos, por meio da formação de intermediários de íons de carbono, ou de complexos de transição com as moléculas-alvo, que podem incluir guaninas e outros componentes do DNA (ALLISON, 2000). A alquilação do DNA consiste basicamente em uma ligação covalente entre as duas fitas da molécula de DNA, impedindo a sua transcrição (OLSON, 2002).

A ciclofosfamida é relativamente inerte até que a ligação fósforo-nitrogênio seja quebrada por meio do metabolismo catalisado pelas enzimas hepáticas do Citocromo P450, as quais são responsáveis pela reação de ativação inicial da droga. Os principais produtos são a 4-hidroxiciclofosfamida e a aldofosfamida. Nas células tumorais, a aldofosfamida sofre clivagem espontânea, com produção de mostarda de fosforamina e acroleína, sendo a primeira responsável pelos efeitos antitumorais através da alquilação do DNA das células tumorais, resultando na ligação cruzada das cadeias dos ácidos nucléicos ou na ligação de um ácido nucléico a uma proteína. Estas alterações danificam seriamente a molécula de DNA, tendo como resultado a morte celular (HARDMAN \& LIMBIRD, 2003). A acroleína é um aldeído $\alpha-\beta$ insaturado altamente eletrofílico, capaz de inibir a proliferação celular e induzir apoptose, mas pouco se sabe sobre seus efeitos moleculares (ALLISON, 2000).

É amplamente relatada na literatura a ação citotóxica da ciclofosfamida. Em geral, a droga causa lesão freqüente nos folículos pilosos, danos em megacariócitos, leucopenia, cardiotoxicidade, congestão vascular pulmonar e necrose hemorrágica miocardial, entre outras patologias (WIERZBA et al., 1998; ALLISON, 2000; HARDMAN \& LIMBIRD, 2003; SERVIÈRE et al., 2003). Além desses efeitos citotóxicos, a ciclofosfamida também induz apoptose em tecidos linfóides e tumorais (BISCHOFF et al., 2000; SCHWARTZ \& WAXMAN, 2001), além de 
gerar radicais livres que causam dano às células epiteliais e endoteliais (SULKOWSKA et al., 1998).

$\mathrm{Na}$ área reprodutiva, sabe-se que a ciclofosfamida induz alterações na função testicular de humanos e roedores e promove infertilidade através de oligospermia, azoospermia e atrofia tubular seminífera (FAIRLEY et al., 1972; SCHAMBERG et al., 1981; KELLY et al., 1992).

De acordo com Anderson et al. (1995), nos modelos animais, os estágios pós-meióticos do ciclo espermatogênico são os mais sensíveis à ação da ciclofosfamida. Matsui et al. (1995) verificaram que houve redução no número de espermatócitos préleptotênicos em testículos de ratos adultos tratados com dose única de $100 \mathrm{mg} / \mathrm{kg}$ de ciclofosfamida.

Gould et al. (1983) descreveram que poucas alterações histológicas ocorreram em testículos de ratos adultos tratados com o agente antitumoral. No entanto, Velez de la Calle et al. (1989) verificaram que houve rompimento da estrutura tubular seminífera, atrofia tubular, vacuolização de células de Sertoli e redução na população de espermatócitos primários e espermátides imaturas em testículos de ratos adultos tratados com ciclofosfamida.

Assim, é de grande interesse a busca de métodos alternativos que reduzam os efeitos colaterais promovidos pela ciclofosfamida e o uso de lipossomas parece corresponder a essa expectativa. Estudo realizado anteriormente em nosso laboratório (PONTES et al., 2004), demonstrou que a incorporação da ciclofosfamida ao lipossoma suprimiu quaisquer efeitos colaterais do fármaco sobre a estrutura morfológica dos testículos e espermatozóides de ratos adultos. O presente estudo visa avaliar, por meio da morfometria e da estereologia, os testículos de ratos adultos submetidos ao tratamento com a ciclofosfamida incorporada ao lipossoma.

\section{Materiais e Métodos}

\section{Animais}

Foram utilizados ratos da linhagem Wistar, sexualmente maduros, com 90 dias de idade. Os animais foram adquiridos do Biotério Central da Universidade Estadual Paulista - Campus de Botucatu. Posteriormente foram alojados no Biotério da Faculdade de Ciências e Letras de Assis UNESP, em ambiente adequado $\left(22^{\circ} \mathrm{C}\right.$ e 12 horas de ciclo claro/escuro), recebendo água e ração $a d$ libitum. O manejo dos animais obedeceu aos princípios éticos adotados pelo Colégio Brasileiro de Experimentação Animal.

\section{Drogas}

Foram utilizadas as seguintes drogas: Agente antineoplásico Ciclofosfamida (Cyclophosphamide Monohydrate - Lab. SIGMA Chem. Co. - USA), de fórmula química $\mathrm{C}_{7} \mathrm{H}_{15} \mathrm{Cl}_{2} \mathrm{~N}_{2} \mathrm{O}_{2} \mathrm{P}-\mathrm{H}_{2} \mathrm{O}$; Lipossoma DL- $\alpha$-Dipalmitoil Fosfatidilcolina (1,2Dihexadecanoyl-Rac-Glycero-3-Phosphocoline Lab. SIGMA Chem. Co. - USA), de fórmula $\mathrm{C}_{40} \mathrm{H}_{80} \mathrm{NO}_{8} \mathrm{P}$; e Colesterol 5-Cholesten-3 $\beta$-Ol (Lab. SIGMA Chem. Co. - USA), de fórmula $\mathrm{C}_{27} \mathrm{H}_{46} \mathrm{O}$. O colesterol, adicionado à estrutura lipoprotéica lipossomal, reduz a habilidade de certas proteínas penetrarem e desorganizarem a bicamada dos lipossomas (SZOKA \& PAPAHADJOPOULOS, 1980).

\section{Preparação do Lipossoma}

A vesícula sintética multilamelar (DPPC) foi preparada com o uso dos métodos descritos por Hope et al. (1985) e Nogueira (1996). Realizou-se a pesagem do DPPC, da ciclofosfamida e do colesterol com base no peso corpóreo dos animais de cada grupo experimental. Em seguida, as drogas foram colocadas em um balão de destilação de $5 \mathrm{~mL}$, adicionando-se $1 \mathrm{~mL}$ de clorofórmio, e a solução foi homogeneizada em um agitador de tubos de ensaio. Evaporou-se o clorofórmio com $\mathrm{N}_{2}$ para que ocorresse a formação do filme fosfolipídico (aproximadamente $2 \mathrm{~h}$ e meia). Posteriormente, foi adicionado ao balão de destilação $2 \mathrm{~mL}$ de Solução Tampão Fosfato $(\mathrm{pH} 7,0)$ para hidratação do filme, e a solução foi homogeneizada novamente no agitador de tubos de ensaio. Colocouse o balão de destilação com a solução em banho- 
Maria à temperatura de $60^{\circ} \mathrm{C}$, em agitação branda. Completou-se o volume com solução Tampão Fosfato até $5 \mathrm{~mL}$, e homogeneizou-se novamente.

\section{Protocolo Experimental}

Os animais foram pesados e casualmente distribuídos em 4 grupos experimentais ( $\mathrm{n}=5 /$ grupo):

A) Controle: os animais receberam uma dose de $1 \mathrm{~mL}$ de solução fisiológica $0,9 \%$ por semana, durante 5 semanas; B) tratado com lipossoma (DPPC): os animais receberam uma dose de $1 \mathrm{~mL}$ do lipossoma por semana, durante 5 semanas; C) tratado com ciclofosfamida (CFM): os animais receberam uma dose de $100 \mathrm{mg} / \mathrm{Kg}$ de peso corpóreo do fármaco, por semana, durante 5 semanas consecutivas; D) tratado com CFM + DPPC: os animais receberam uma dose de $1 \mathrm{~mL}$ da preparação da ciclofosfamida incorporada ao DPPC por semana, durante 5 semanas consecutivas. A escolha da dose de ciclofosfamida baseou-se em estudos prévios em animais experimentais (VELEZ de la CALLE et al., 1989; MATSUI et al., 1995; KAUR et al., 1997). A alta dose utilizada no estudo teve como objetivo induzir as alterações testiculares, para que pudesse ser avaliado o efeito protetor do lipossoma na gônada.

Os fármacos e a solução fisiológica foram administrados intraperitonealmente, devido à facilidade de aplicação. De acordo com Delgado $e t$ al. (1989), esta via de administração de lipossoma mostrou-se eficiente. O sacrifício dos animais foi realizado uma semana após o final do tratamento nos diferentes grupos experimentais.

\section{Processamento Histológico}

Os ratos de cada grupo foram sacrificados por intermédio de saturação anestésica por inalação de éter etílico. As gônadas foram coletadas, pesadas e fixadas em solução alcoólica de Bouin. Procedeu-se à rotina histológica usual (BEHMER et al., 1976), realizando-se as etapas de desidratação, diafanização e inclusão em Paraplast (Oxford-Labware, St. LouisMO, USA). Secções histológicas de $5 \mathrm{~mm}$ de espessura foram coradas através das técnicas de HE e PAS/H, e analisadas em microscopia de luz (Leica modelo DMLS). As imagens histológicas foram obtidas através do uso do analisador de imagens Image Pro Plus Media $\odot$ Cybernetics versão 3.0.1, com a objetiva microscópica de 10x.

\section{Análise Estereológica}

A análise estereológica consistiu nos cálculos das densidades de volume $(\mathrm{Vv})$ do parênquima testicular (túbulos seminíferos) e do tecido intersticial, utilizando-se a ocular integradora de 100 pontos, num aumento final de 100X, totalizando a contagem de 3000 pontos por testículo (MANDARIM-DE-LACERDA, 1995). Os volumes dos tecidos básicos (túbulos seminíferos e tecido intersticial), componentes dos testículos, foram calculados em $\mathrm{cm}^{3}$, a partir da porcentagem relativa a cada gônada, e foram obtidos através da densidade de volume dos tecidos e do volume testicular total.

\section{Análise Morfométrica}

A análise morfométrica conssitiu na (o): 1determinação dos pesos testiculares, em gramas; 2cálculo do volume líquido do testículo $\left(\mathrm{cm}^{3}\right)$, que foi obtido pela subtração do peso da albugínea e do mediastino testicular do peso bruto da gônada (FRANÇA, 1991); 3- determinação da média do diâmetro, em $\mu \mathrm{m}$ (através do menor eixo) e média da área total $\left(\mathrm{em} \mu \mathrm{m}^{2}\right)$ dos túbulos seminíferos, por meio de mensuração de 10 secções tubulares transversais, por testículo, na objetiva de 10X. A análise foi realizada com o uso do analisador de imagens Image Pro Plus Media@ Cybernetics versão 3.0.1.

\section{Índice de Mortalidade}

O índice de mortalidade dos animais foi calculado tendo como base a relação: número de óbitos /número total de animais do grupo x 100.

\section{Análise Estatística}

Para a análise estatística, foi utilizado o programa computacional "Statistica" versão 5.5. Os dados 
foram avaliados pela análise de variância paramétrica no modelo inteiramente casualizado, e as médias obtidas de cada grupo experimental foram comparadas pelo Teste de Tukey (5\%). Os resultados foram considerados significativos quando $\mathrm{p}<0,05$.

\section{Resultados}

\section{Aspectos histológicos}

A análise dos testículos, ao microscópio óptico, mostrou que nos grupos controle (Fig. 1A), tratado com lipossoma (Fig. 1B) e tratado com ciclofosfamida incorporada ao lipossoma (Fig. 1C), a estrutura dos túbulos seminíferos apresentou integridade morfológica, caracterizada pela presença de várias camadas celulares no epitélio germinativo e espermatozóides no lúmen. Nos ratos tratados unicamente com a ciclofosfamida (Fig. 1D), os túbulos seminíferos apresentaram perda de elementos germinativos, depleção epitelial e ausência ou falta de liberação de espermatozóides no lúmen.
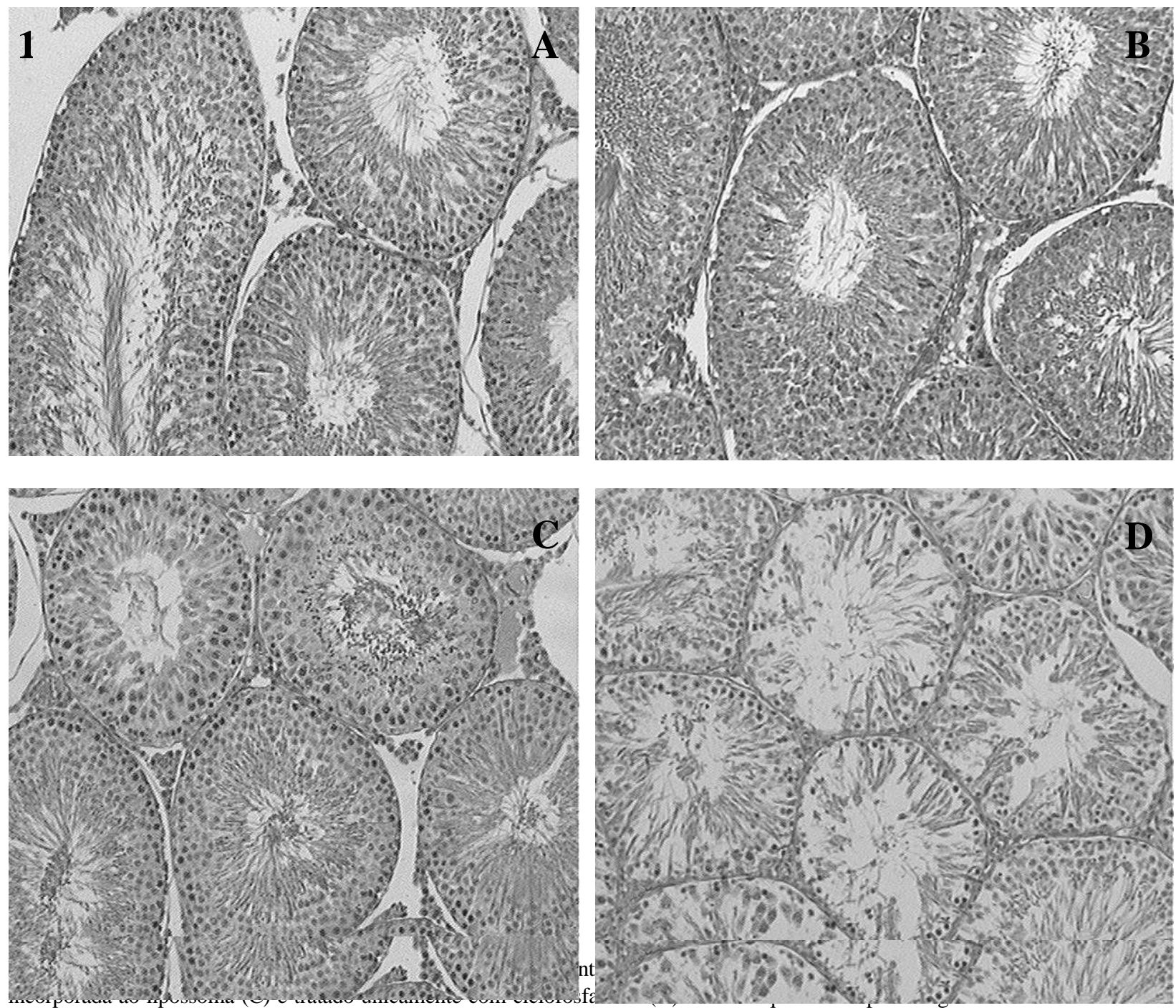

seminíferos em A, B e C. Em D, observar a presença de túbulos seminíferos com ausência de células germinativas no epitélio. HE, obj. 10x.

Semina: Ciências Biológicas e da Saúde, Londrina, v. 27, n. 2, p. 105-1 16, jul./dez. 2006 


\section{Dados estereológicos}

A análise dos dados estereológicos dos túbulos seminíferos testiculares permitiu verificar que houve uma redução significativa $(\mathrm{p}<0,05)$ nos valores médios do volume testicular total e do volume do parênquima nos ratos tratados com ciclofosfamida em relação aos animais dos demais grupos experimentais (Tabela 1).

A Densidade de Volume (Vv) de parênquima nos animais do grupo tratado com ciclofosfamida, foi menor, quando comparada ao resultado obtido no grupo tratado com a droga incorporada ao lipossoma (Tabela 2). No caso específico de incorporação da droga ao lipossoma, o parênquima testicular representou aproximadamente $63,4 \%$ do volume total do órgão, enquanto no grupo tratado apenas com ciclofosfamida, o volume foi de apenas 58,9\%.

Tabela 1. Volume líquido do testículo, do parênquima testicular e do tecido intersticial dos animais dos diferentes grupos experimentais (média \pm desvio padrão).

\begin{tabular}{c|c|c|c}
\hline $\begin{array}{c}\text { Grupos } \\
\text { Experimentais }\end{array}$ & $\begin{array}{c}\text { Volume testicular total } \\
\left(\mathbf{c m}^{\mathbf{3}}\right)\end{array}$ & $\begin{array}{c}\text { Volume do parênquima } \\
\left(\mathbf{c m}^{\mathbf{3}}\right)\end{array}$ & $\begin{array}{c}\text { Volume do tecido } \\
\text { intersticial }\left(\mathbf{c m}^{\mathbf{3}}\right)\end{array}$ \\
\hline Controle & $2,89 \pm 0,44 \mathrm{a}$ & $2,14 \pm 0,59 \mathrm{a}$ & $0,75 \pm 0,26 \mathrm{a}$ \\
\hline $\mathrm{DPPC}$ & $2,99 \pm 0,12 \mathrm{ac}$ & $2,06 \pm 0,02 \mathrm{ac}$ & $0,92 \pm 0,19 \mathrm{a}$ \\
\hline $\mathrm{CFM}$ & $2,08 \pm 0,16 \mathrm{~b}$ & $1,22 \pm 0,09 \mathrm{~b}$ & $0,86 \pm 0,12 \mathrm{a}$ \\
\hline $\mathrm{CFM}+\mathrm{DPPC}$ & $2,49 \pm 0,20 \mathrm{ac}$ & $1,58 \pm 0,09 \mathrm{ac}$ & $0,91 \pm 0,13 \mathrm{a}$ \\
\hline
\end{tabular}

* letras iguais na mesma coluna não diferem estatisticamente entre si $(p>0,05)$.

$\mathrm{DPPC}=$ grupo tratado com lipossoma; $\mathrm{CFM}=$ grupo tratado com ciclofosfamida;

$\mathrm{CFM}+\mathrm{DPPC}=$ grupo tratado com ciclofosfamida incorporada ao lipossoma.

Tabela 2. Valores percentuais do parênquima e do tecido intersticial sobre o volume total da gônada dos animais dos diferentes grupos experimentais.

\begin{tabular}{c|c|c}
\hline Grupos Experimentais & Parênquima (\%) & Tecido Intersticial (\%) \\
\hline Controle & 73,3 & 27,7 \\
\hline DPPC & 69,8 & 30,2 \\
\hline CFM & 58,9 & 41,1 \\
\hline CFM + DPPC & 63,4 & 36,6 \\
\hline
\end{tabular}

$\mathrm{DPPC}=$ grupo tratado com lipossoma $; \mathrm{CFM}=$ grupo tratado com ciclofosfamida $; \mathrm{CFM}+\mathrm{DPPC}=$ grupo tratado com ciclofosfamida incorporada ao lipossoma.

\section{Dados morfométricos}

Após a incorporação da ciclofosfamida ao lipossoma, o volume líquido do testículo (Tabela1) apresentou aumento significativo $(\mathrm{p}<0,05)$ em relação ao grupo tratado apenas com ciclofosfamida e não diferiu daquele do grupo controle.

A análise dos dados morfométricos dos túbulos seminíferos testiculares (Tabela 3) permitiu verificar que, no grupo tratado apenas com o lipossoma DPPC, houve redução significativa $(\mathrm{p}<0,05)$ na área tubular e no diâmetro dos túbulos seminíferos, em comparação aos demais grupos experimentais, com exceção do grupo tratado apenas com a droga ciclosfosfamida. Quanto ao peso testicular, observouse um aumento no grupo tratado com a ciclofosfamida incorporada ao lipossoma, mas este aumento não foi 
significativo em relação ao peso testicular do grupo tratado apenas com a droga ciclofosfamida.

\section{Índice de Mortalidade}

A ciclofosfamida manifestou seus potentes efeitos colaterais pela presença de piloereção e feridas perioculares nos animais que receberam somente o tratamento com o agente oncolítico. Estes efeitos não foram observados nos ratos dos demais grupos experimentais.
Nos grupos controle e tratado com o lipossoma, o índice de mortalidade foi de $0 \%$. Nos grupos tratados com a ciclofosfamida e com a droga incorporada ao lipossoma, os índices de mortalidade foram respectivamente, de $40 \%$ e $35,7 \%$. Nesses dois grupos experimentais, houve a necessidade de se recompor a amostra de animais, de forma a manter o padrão de $n=5 /$ grupo, para as avaliações do estudo.

Tabela 3. Morfometria dos testículos dos ratos dos diferentes grupos experimentais (média \pm desvio padrão).

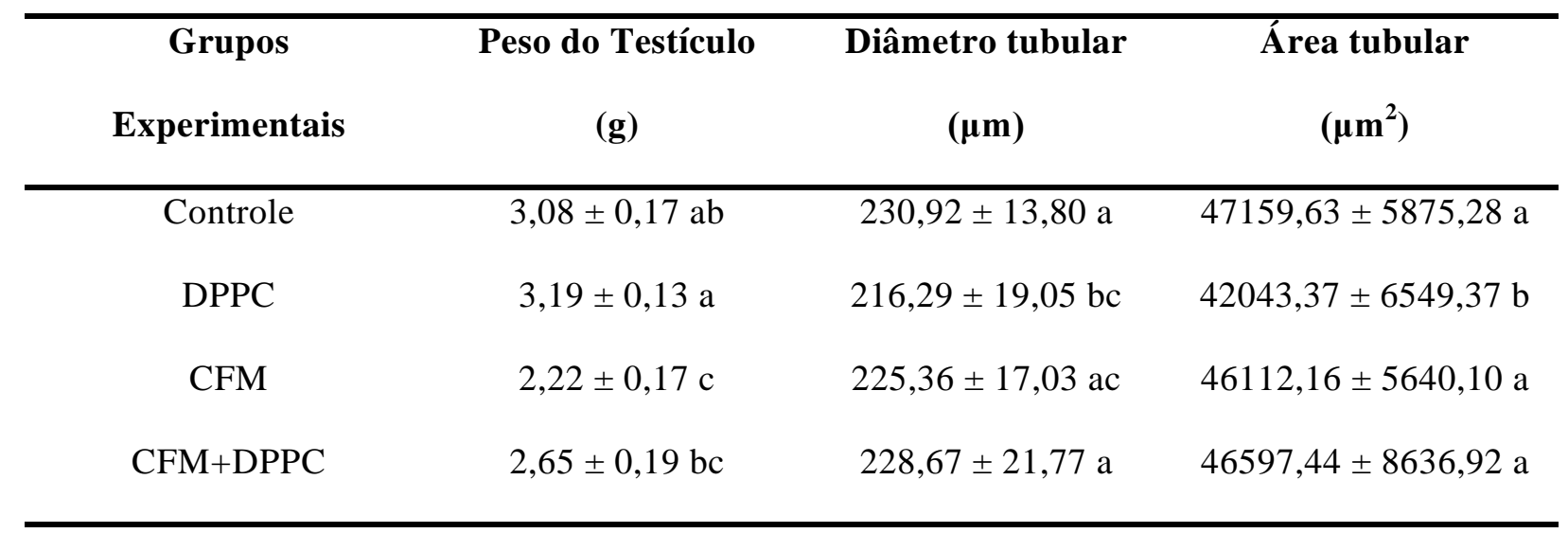

* letras iguais na mesma coluna não diferem estatisticamente entre si $(\mathrm{p}>0,05)$.

$\mathrm{DPPC}=$ grupo tratado com lipossoma $\mathrm{CFM}=$ grupo tratado com ciclofosfamida;

$\mathrm{DPPC}+\mathrm{CFM}=$ grupo tratado com ciclofosfamida incorporada ao lipossoma.

\section{Discussão}

Vários métodos têm sido empregados com a finalidade de diminuir os efeitos colaterais de drogas sobre a reprodução. A utilização de análogos de GnRH para suprimir estes efeitos surgiu como uma boa tentativa de oferecer uma melhor vida póstratamento a pacientes sob a ação de agentes quimioterápicos para o câncer. Porém, sua eficácia ainda é muito discutida na comunidade científica, pois alguns estudos apontam o sucesso dos resultados (GLODE et al., 1981; PARCHURI et al., 1993), enquanto outros discordam dessa posição (PAPADOPOULOS, 1991). A diferença entre os resultados obtidos em vários laboratórios foi apontada por MORRIS (1993), de modo que ainda são necessários vários estudos acerca da eficácia desses tratamentos. Outras interações entre fármacos e agentes quimioterápicos apontam para o sucesso na diminuição dos efeitos colaterais da droga, como no caso das interações com amifostina (SOUZA et al., 2000, LIRDI, 2003) e extratos vegetais (XU \& MALAVÉ, 2001), mas poucos são os relatos de redução dos efeitos colaterais da droga sobre a reprodução de mamíferos (LIRDI, 2003).

O efeito do agente antineoplásico ciclofosfamida na espermatogênese de mamíferos tem sido discutido em estudos morfofisiológicos (TRASLER et al., 1985; VELEZ de la CALLE et al., 1989; RUSSEL \& RUSSEL, 1991; PONTES et al., 2004), e genéticos (ANDERSON et al., 1995; SCHIMENTI et al., 1997; SAWYER \& BROWN, 2000; AGUILAR- 
MAHECHA et al., 2002). A ciclofosfamida é um potente agente promotor de infertilidade em mamíferos, mantendo o indivíduo infértil por um longo período de tempo pós-tratamento ou, em alguns casos, permanentemente, dependendo da dosagem utilizada e do tempo de exposição à droga.

No presente estudo, diferenças significativas foram observadas entre os valores médios do volume do parênquima testicular e do volume líquido do testículo dos ratos tratados com ciclofosfamida em relação aos animais dos demais grupos experimentais. Estas variações refletem o comprometimento dos testículos dos animais tratados exclusivamente com ciclofosfamida, e demonstram ainda que, com a incorporação da droga ao lipossoma, este comprometimento foi atenuado.Isso ocorre devido ao aumento do volume de parênquima testicular observado, o qual não diferiu estatisticamente dos volumes do parênquima testicular dos animais dos grupos controle e tratado com lipossoma. O grupo tratado com ciclofosfamida não incorporada ao lipossoma também demonstrou menor relação percentual do volume do parênquima testicular em relação ao volume total do órgão, em comparação aos ratos dos grupos controle e tratado com ciclofosfamida incorporada ao lipossoma, sugerindo que o efeito citotóxico da droga foi atenuado neste grupo, provavelmente, pela incorporação da droga ao lipossoma.

Estudos anteriores realizados em nosso laboratório demonstraram que a incorporação dos agentes oncolíticos ciclofosfamida (PONTES et al., 2004) e cisplatina (FAVARETO et al., 2004) ao lipossoma Dipalmitoil Fosfatidilcolina foi benéfica para manter a integridade morfológica do epitélio seminífero dos testículos de ratos adultos. O presente estudo mostra, sob o ponto de vista estereológico, que os efeitos colaterais promovidos pela ciclofosfamida foram suprimidos. Este resultado sugere que a gônada masculina também é capaz de absorver lipossomas injetados no organismo, assim como acontece com outros órgãos e tecidos, tais como fígado, rins, pulmões, cérebro e músculo esquelético
(GREGORIADIS, 1976). De acordo com OKU et al. (1997), o uso de lipossomas no tratamento de câncer de pulmão pode inibir marcadamente a metástase no tecido lesado. Resultados obtidos por CAMARGO et al. (2001) indicaram que a incorporação do agente esquistossomicida oxamniquine ao lipossoma Dimiristoil Fosfatidilcolina (DMPC), foi capaz de proteger as células germinativas, devido ao fato das vesículas lipossomais atuarem como uma eficiente membrana biológica e, neste sentido, foi capaz de suprimir os efeitos colaterais da droga sobre os testículos de cobaias adultas.

É relatado na literatura (GLODE et al., 1981; SATO et al., 1993; CAMARGO et al., 2000) que os agentes alquilantes têm a capacidade de promover atrofia tubular seminífera em roedores de laboratório. No entanto, no presente estudo, não houve efeito significativo do tratamento com a ciclofosfamida incorporada ou não ao lipossoma, sobre os resultados morfométricos dos túbulos seminíferos testiculares. A redução no diâmetro dos túbulos seminíferos e na área tubular, verificada nos testículos dos animais tratados apenas com o lipossoma não era esperada, uma vez que se trata de um agente inócuo ao organismo. Embora a análise morfométrica tenha apontado para uma possível atrofia tubular nos testículos destes animais, a morfologia tubular seminífera manteve-se íntegra (PONTES et al., 2004). As discrepâncias nos resultados morfométricos verificados em vários estudos que utilizaram agentes quimioterapêuticos para o câncer se devem às diferenças entre as dosagens e esquemas de administração da droga, espécies, linhagens e idade dos modelos experimentais. SANTOS et al. (2006) trataram camundongos com $150 \mathrm{mg} / \mathrm{kg}$ de peso corpóreo de ciclofosfamida e não observaram efeitos tóxicos nos animais.

A ausência de mortalidade no grupo tratado somente com lipossoma comprova relatos anteriores (GREGORIADIS et al., 1971; LIDGATE et al., 1988) de que este agente farmacológico tem a capacidade de ser um veículo não tóxico para as 
drogas. No entanto, verificou-se, no presente estudo, uma alta taxa de mortalidade nos animais tratados com a ciclofosfamida incorporada ao lipossoma. Este resultado sugere que a droga foi tóxica para o animal, afetando outros órgãos não analisados neste estudo, embora a incorporação da ciclofosfamida ao lipossoma tenha-se mostrado eficiente em proteger o testículo, especialmente quanto ao aspecto estereológico (PONTES et al., 2004).

GLODE et al. (1981) demonstraram que interações medicamentosas entre a ciclofosfamida e outros fármacos, benéficas em proteger o testículo da ação da droga, não foram capazes de deter os potentes efeitos colaterais da droga sobre outros locais do organismo, causando também consideráveis taxas de mortalidade e sintomas como piloereção e perda de peso, também verificados no presente estudo. As altas taxas de mortalidade não devem ser consideradas um fator negativo da associação ciclofosfamida-lipossoma, uma vez que utilizou-se uma concentração de ciclofosfamida suficientemente alta para que este agente alquilante pudesse vencer a barreira testicular e causar danos ao tecido. No entanto, vários estudos ainda são necessários a fim de que se comprove a eficiência da incorporação de fármacos aos lipossomas em doses terapêuticas. A mortalidade verificada no grupo tratado com a ciclofosfamida é concordante com os resultados obtidos por vários autores (GOULD et al., 1983; TRASLER et al., 1988; VELEZ de la CALLE et al., 1989).

O presente estudo demonstrou que o lipossoma atenuou os efeitos tóxicos promovidos pela ciclofosfamida sobre a estereologia de testículos de ratos adultos. Acreditamos que este resultado, aliado àqueles previamente conduzidos (CAMARGO et al., 2001; FAVARETO et al., 2004; PONTES et al., 2004), deve servir como uma primeira tentativa para estudos posteriores, a fim de que possa ser concluído que o lipossoma apresenta efeito protetor sobre a reprodução de mamíferos, sobretudo no que diz respeito à possibilidade dos lipossomas também protegerem os gametas de alterações genéticas e moleculares que estes possam sofrer quando expostos à ação de fármacos. A interpretação dos resultados obtidos no modelo animal para a espécie humana deve ser amplamente investigada por vários estudos, nos quais sejam usadas diferentes espécies animais e empreguem-se dosagens normalmente utilizadas no tratamento terapêutico.

\section{Agradecimentos}

Os autores agradecem a Sra. Maria Isabel de Oliveira, do Departamento de Ciências Biológicas (UNESP, Assis, SP - Brasil), por sua ajuda técnica. Também expressam sua gratidão à Fundação de Amparo à Pesquisa do Estado de São Paulo (FAPESP), São Paulo - SP, Brasil, pelo apoio financeiro.

\section{Referências}

ALLISON, A.C. Immunosuppressive drugs: the first 50 years and a glance forward. Immunopharmacology, Amsterdam, v.47, p.63-83, 2000.

ANDERSON, D.; BISHOP, J.B.; GARNER, R.C.; OSTROSKYWEGMAN, P.; SELBY, P.B. Cyclophosphamide - Review of its mutagenicity for an assessment of potential germ-cell risks. Mutation Research, Amsterdam, v.330, p.115-181, 1995.

BEHMER, O.A.; TOLOSA, E.M.C.; FREITAS NETO, A.G. Manual de técnicas para histologia normal e patológica. EDART, USP: São Paulo, 1976.

BISCHOFF, P.L.; HOLL, V.; COELHO, D.; DUFOUR, P.; WELTIN, D.; LUU, B. Apoptosis at the interface of immunosuppressive and anticancer activities: the examples of two classes of chemical inducers. Current Medicinal Chemistry, San Francisco, v.7, p.693-713, 2000.

CAMARGO, I.C.C.; TSE, M.C.P.; TSE, H.G.; PADOVANI, C.R.; ARAGON, F.F. Estudo morfométrico em testículos e epidídimos de cobaias (Cavia porcellus, L.) submetidas experimentalmente a oxamniquine durante o desenvolvimento pós-natal. Naturalia, Rio Claro, v.25, p.23-38, 2000 .

CAMARGO, I.C.C.; NOGUEIRA, L.C.; DEBUS, G.V. Morphological evaluation of the testes in adult guinea pigs (Cavia porcellus, L.) treated with oxamniquine incorporated into synthetic phospholipid (dimyristoil phosphatidylcholine) vesicles. Brazilian Journal of Morphological Science, Campinas, v.18, p.29-34, 2001. 
DELGADO, G.; POTKULL, R.K.; TREAT, J.A.; LEWANDOWSKI, G.S.; BATRER, J.F. A phase I/II study of intraperitoneally administered doxorubicin entrapped in cardiolipin liposomes in patients with ovarian cancer. American Journal of Obstetrics and Gynecology, New York, v.160, p.812-819, 1989.

FAIRLEY, K.F.; BARRIE, J.U.; JOHSON, W. Sterility and testicular atrophy related to cyclophosphamide therapy. Lancet, London, v.1, p.568-569, 1972.

FAVARETO, A.P.A.; PONTES, D.A.; CAMARGO, I.C.C.; NOGUEIRA, L.C.; FREI, F.; MESQUITA, S.P.; FARIA, M.J.S. Efeito da interação do agente oncolítico cisplatina ao lipossoma Dipalmitoil Fosfatidilcolina sobre aspectos morfológicos de testículos de ratos adultos. In: XVI Congresso de Iniciação Científica da UNESP, Ilha Solteira - SP, 2004. Divulgação eletrônica.

FIELDING, R.M. Liposomal drug delivery - Advantages and limitations from a clinical pharmacokinetic and therapeutic perspective. Clinical Pharmacokinetics, Auckland, v.21, p.155-164, 1991.

FRANÇA, L.R. Análise morfofuncional da espermatogênese de suínos adultos da raça Piau. Belo Horizonte: UFMG, ICB, 1991, 180p. (Tese, Doutorado).

GLODE, L.M.; ROBINSON, J.; GOULD, S.F. Protection from cyclophosphamide induced testicular damage with an analogue of gonadotropin-releasing hormone. Lancet, London, p.1132-1134, 1981.

GOULD, S.F.; POWELL, D.; NETT, T. A rat model chemotherapy-induced male infertility. Archives of Andrology, New York, v. 11, p. 141-150, 1983.

GREGORIADIS, G. The Carrier Potential of Liposomes in Biology and Medicine (first of two parts). New England Journal of Medicine, Boston, v.295, p.704-708, 1976.

GREGORIADIS, G.; LEATHWOOD, P.D.; RYMAN, B.E. Enzyme entrapment in Liposomes. FEBS Letters, Amsterdam, v.14, p.95-99, 1971.

HARDMAN, J.G.; LIMBIRD, L.E. Quimioterapia das doenças neoplásicas: antineoplásicos. In: GOODMAN, L.S.; GILMAN, A. As bases farmacológicas da terapêutica. 10 ed. Rio de Janeiro: McGraw Hill, 2003. p. 1041-1097.

HOPE, M.J.; BALLY, M.B.; EWBB, G.; CULLIS, P.R. Production of large unilamellar vesicles by a rapid extrusion procedure. Characterization of size distribution, trapped volume and ability to maintain a membrane potential. Biochemical and Biophysical Acta, Amsterdam, v.812, p.55-65, 1985.

JULIANO, R.L. Pharmacokinetics of Liposomeencapsulated drugs. In: KNIGHT (Ed.) Liposomes: from physical structure to therapeutic applications. Amsterdam: Elsevier/North Holland Biomedical Press, 1981. p. 391-406.
KAUR, F.; SANGHA, G.K.; BILASPURI, G.S. Cyclophosphamide-induced structural and biochemical changes in the testis and epididymis of rats. Indian Journal of Experimental Biology, New Delhi, v. 35, p. 771-775, 1997.

KELLY, S.M.; ROBAIRE, B.; HALES, B.F. Paternal cyclophosphamide treatment causes post-implantation loss via inner cell mass-specific cell death. Teratology, New York, v.45, p.313-318, 1992.

KIM, S.; KIM, D.J.; GEYER, M.A.; HOWELL, S.B. Multivesicular liposomes containing 1-B-DArabinofuranosylcytosine for slow-release intrathecal therapy. Cancer Research, Philadelphia, v. 47, p. 3935-3937, 1987.

LEVY, G. Targeted drug delivery - some pharmacokinetic considerations. Pharmacological Research, London, v.4, p.3-4, 1987.

LIDGATE, D.M.; FELGNER, P.L.; FLEITMAN, J.S.; WHATLEY, J.; FU, R.C-C. In vitro and in vivo systems studies evaluating a liposome system for drug solubilization. Pharmacological Research, London, v.5, p.759-764, 1988.

LIRDI, L.C. Ação protetora da amifostina (WR2721) sobre o epitélio seminífero de ratos albinos submetidos ao tratamento com cisplatina, na fase pré-púbere. São Paulo: UNIFESP-EPM, 2003, 118 p. (Tese, Mestrado).

MANDARIM-DE-LACERDA， C.A. Métodos quantitativos em morfologia. Rio de Janeiro: EDUERJ, 1995.

MATSUI, H.; MITSUMORI, K.; YASUHARA, K.; ONODERA, H.; SHIMO, T.; TAKAHASHI, M. Morphological evaluation of cyclophosphamide testicular toxicity in rats using quantitative morphometry of spermatogenic cycle stages. Journal of Toxicology Science, v. 20, p. 407-414, 1995.

MORRIS, I.D. Protection against cytotoxic-induced testis damage - experimental approaches. European Urology, Basel, v.23, p.143-147, 1993.

NOGUEIRA, L.C. Supressão de emissão de compostos fluorescentes em meios organizados. Ribeirão Preto: FFCLRP- USP, 1996, 118 p. (Tese, Doutorado).

OKU, N.; KOIKE, C.; TOKUDOME, Y.; OKADA, S.; NISHIKAWA, N.; TSUKADA, H.; KISO, M.; HASEGAWA, A.; FUJII, H.; MURATA, J.; SAIKI, I. Application of liposomes for cancer metastasis. Advanced Drug Delivery Reviews, New York, v.24, p.215-223, 1997.

OLSON, J.M. Farmacologia Clínica Fácil. Rio de Janeiro: Revinter, 2002.

PAPADOPOULOS, I. LHRH analogues do not protect the germinal epithelium during chemotherapy. An experimental animal investigation. Urological Research, Berlin, v.19, p.31-34, 1991. 
PARCHURI, N.; WILSON, G.; MEISTRICH, M.L. Protection by gonadal-steroid hormones against procarbazine-induced damage to spermatogenic function in lbnf1 hybrid rats. Journal of Andrology, Philadelphia, v.14, p.257-266, 1993.

PONTES, D.A.; FAVARETO, A.P.A.; CAMARGO, I.C.C.; NOGUEIRA, L.C.; MESQUITA S.F.P.; FARIA, M.J.S. Efeito da incorporação do agente antineoplásico ciclofosfamida ao lipossoma dipalmitoil fosfatidilcolina sobre aspectos morfológicos de testículos de ratos adultos. In: VI Congresso Londrinense de Biologia Aplicada à Saúde e I Simpósio Paranaense de Patologia Experimental, Londrina - PR, 2004. Divulgação eletrônica.

RUSSEL, L.D; RUSSEL, J.A. Short-term morphological response of the rat testis to administration of five chemotherapeutic agents. The American Journal of Anatomy, Maryland, v.192, p.142-168, 1991.

SANTOS, F.V.; MESQUITA, S.F.P.; FARIA, M.J.S.S.; POERSH, A.; MACIEL, M.A.; PINTO, A.C.; MORIMOTO, H.K.; CÓLUS, I.M.S. Absence of mutagenicity and germ cells of mice submitted to subchronic treatment with an extract of Croton cajucara Benth (Euphorbiaceae). Genetics and Molecular Biology, Ribeirão Preto, v.29, p.159-165, 2006.

SATO, M.; FURUKAWA, F.; NISHIKAWA, A.; IMAZAWA, T.; YOSHIMURA, H.; SUZUKI, J.; NAKAMURA, K.; TAKAHASHI, M. Effects of cyclophosphamide on spontaneous testicular and pancreatic lesions in wbn/kob rats. Eisei Shikenjo Hokoku, Tokyo, v.111, p.34-38, 1993.

SAWYER, D.E.; BROWN, D.B. Diminished decondensation and DNA synthesis in activated sperm from rats treated with cyclophosphamide. Toxicology Letters, Amsterdam, v.114, p.19-26, 2000.

SCHAMBERG, R.C.; ROSEMBERG, S.A.; SEIPP, C.A. Effects of high dose methotrexate and vincristine on ovarian and testicular functions in patients undergoing postoperative adjuvant treatment of osteosarcoma. Cancer Treatment Reviews, London, v.65, p.739-746, 1981.

SCHIMENTI, K.J.; HANNEMAN, W.H.; SCHIMENTI, J.C. Evidence for cyclophosphamide-induced gene conversion and mutation in mouse germ cells. Toxicology and Applied Pharmacology, New York, v.147, p.343-350, 1997.

SCHWARTZ, P.S.; WAXMAN, D.J. Cyclophosphamide induces caspase 9-dependent apoptosis in 9L tumor cells. Molecular Pharmacology, Baltimore, v.60, p.1268-1279, 2001.

SCULIER, J.P.; BRASSINE, C.; LADURON, C.; DELCROIX, C.; HOLLAERT, C. Phase I study, with pharmacokinetic analysis, of intravenous administration of 6aminochrysene entrapped in sonicated liposomes in patients with advanced cancer. Journal of Liposome Research, New York, v. 1, p. 177-193, 1989.

SERVIÈRE, J.; DUBAYLE, D.; MENÉTREY, D. Increase of rat medial habenular mast cell numbers by systemic administration of cyclophosphamide. Toxicology Letters, Amsterdam, v.145, p.143-152, 2003.

SOUZA, C.A.; SANTINI, G.; MARINO, G.; NATI, S.; CONGIU, A.M.; VIGORITO, A.C.; DAMASIO, E. Amifostine (wr-2721), a cytoprotective agent during highdose cyclophosphamide treatment of non-Hodgkin's lymphomas: a phase II study. Brazilian Journal of Medical and Biological Research, São Paulo, v.33, p.791798, 2000.

SULKOWSKA, M.; SULKOWSKI, S.; SKRZYDLEWSKA, E.; FARBISZEWSKI, R.; Cyclophosphamide-induced generation of reactive oxygen species. Comparison with morphological changes in type II alveolar epithelial cells and lung capillaries. Experimental and Toxicological Pathology, New York, v.50, p.209-220, 1998.

SZOKA, F.; PAPAHADJOPOULOS, D. Comparative properties and methods of preparation of lipid vesicles (Liposomes). Annual Review Biophysics and Bioenginners, Palo Alto, v.9, p.467-508, 1980.

TRASLER, J.M.; HALES, B.F.; ROBAIRE, B. Paternal cyclophosphamide treatment of rats causes fetal loss and malformation without affecting male fertility. Nature, London, v.316, p.144-146, 1985.

TRASLER, J.M.; HERMO, L.; ROBAIRE, B. Morphological changes in the testis and epididymis of rats treated with cyclophosphamide: a quantitative approach. Biology of Reproduction, Madison, v.38, p.463-479, 1988.

VELEZ de la CALLE, J.F.; QUEIROZ, F; GARNIER, D.H; KERCRET, H.; FOLLIOT, R.; JÉGOU, B. Reproductive effects of the anticancer drug cyclophosphamide in male rats at different ages. Archives of Andrology, New York, v.22, p.251-263, 1989.

VIGIL, P.; BUSTOS-OBREGON, E. Alkylating agents and mouse spermatogenesis: Effects of a single injection of cyclophosphamide. Andrology, New York, v. 17, p. 276282, 1985.

WIERZBA, K.; YAMADA, Y.; HANANO, M. Cytostatics and immunosuppressive drugs. In: DUKES, M.N.G.; BEELEY L. Side effects of drugs annual. vol. 12. Amsterdam: Excerpta Medica, 1998. p 380.

XU, X.; MALAVÉ, A. Protective effect of Berberine on Cyclophosphamide-induced haemorrhagic cystitis in rats. Pharmacology \& Toxicology, Copenhagen, v.88, p.232237, 2001. 
